\title{
ELEVATED PLASMA LEVEL OF LEUKOTRIENES IN BRONCHIAL ASTHMA PATIENTS: A POSSIBLE CLINICAL RELEVANCE
}

\author{
MAHMOUD MANSOUR*, NABIL FAROUK ${ }^{\dagger}$, ABBAS EL MARAGY $^{\dagger}$, IBRAHIM RADWAN $^{\dagger}$, \\ OMAR EL-AHMADY* \\ * Tumor Marker Oncology Research Center, Al-Azhar University, \\ ${ }^{\dagger}$ Chest Department, Faculty of Medicine, Al-Azhar University, Cairo, Egypt
}

\begin{abstract}
SUMMARY
Plasma from bronchial asthma patients and healthy controls was investigated for the content of lipoxygenase products. After lipid extraction using SEP-PAK $\mathrm{C}_{18}$ Cartridges, the lipoxygenase products were measured by Enzyme-Immunoassay. Elevated chemotactic $\mathrm{B}_{4}$ was found in plasma from asthmatic patients with mean value $(483 \pm 75) \mathrm{pmol} / \mathrm{L}$, while the mean value in normal healthy donors was $(140 \pm 12.1) \mathrm{pmol} / \mathrm{L}(\mathrm{M} \pm \mathrm{SE})$. The levels of spasmogenic cysteinyl containing leukotrienes were also very high in the bronchial asthma patients. Elevations of leukotriene $\mathrm{B}_{4}$ and cysteinyl containing leukotrienes were detected during attacks of bronchial asthma. These results suggest that leukotriene $\mathrm{B}_{4}$ may be important in the pathogenesis of bronchial asthma and confirmed that peptidoleukotrienes play a role as chemical mediators during the asthmatic attack.
\end{abstract}

KEY WORDS Leukotrienes $\mathrm{C}_{4}$ and $\mathrm{B}_{4} \quad$ Bronchial asthma

\section{INTRODUCTION}

Stechschulte et al. (1973) reported the presence of a slow reacting substance (SRS-A) in the plasma of guinea pigs during anaphylaxis. Murphy et al. (1979) subsequently elucidated the structure of SRS-A and showed it to be composed of leukotrienes.

The first step in the biosynthesis of leukotrienes is oxidation of arachidonic acid at carbon atom 5 (Samuelsson et al., 1987), the reaction is catalyzed by 5-lipoxygenase enzyme forming the unstable epoxide leukotriene $A_{4}$. This highly reactive intermediate can either be hydrolysed by $\mathrm{LTA}_{4}$ hydrolase, forming $\mathrm{LTB}_{4}$, or enzymatically conjugated with gluthathione, (reaction catalyzed by $\mathrm{LTC}_{4}$ synthase) leading to $\mathrm{LTC}_{4}$ formation. The latter compound is metabolized to leukotrienes $\mathrm{D}_{4}$ and $\mathrm{E}_{4}$ by successive elimination of a glutamyl and glycine residue.

The cysteinyl-containing leukotrienes are potent bronchoconstrictors that increase vascular permeability in postcapillary venules and stimulate mucus secretion. Thus leukotrienes $\mathrm{C}_{4}, \mathrm{D}_{4}$ and $\mathrm{E}_{4}$, which are released from the lung tissue of asthmatic patients exposed to specific antigens, appear to play a pathophysiological role in immediate hypersensitivity reactions (Samuelsson, 1983).

Correspondence to: Omar El-Ahmady, Head of Tumor Marker Onocology Research Center, 2 Roshdy st., Safeer Square, Heliopolis, Cairo, Egypt. Tel. 202 2626655; Fax 2022625796. 
In contrast, $\mathrm{LTB}_{4}$ causes adhesion and chemotactic movement of leukocytes, stimulating aggregation, enzyme release and superoxide anion generation in neutrophils. Less is known about whether $\mathrm{LTB}_{4}$ is responsible for bronchial asthma and insufficient evidence is available to assess the true role of $\mathrm{LTB}_{4}$ in this condition.

The aim of the present study was to add more information on the role of $\mathrm{LTB}_{4}$ in asthmatic patients during wheezing attack, comparing the observed plasma levels with those in healthy controls.

\section{MATERIALS AND METHODS}

\section{Subjects}

34 Asthmatic patients who met the criteria for bronchial asthma and 10 healthy controls were studied. All the asthmatics were out-patients and when they came to the clinic because of a wheezing attack, arterial blood gas analysis was done to determine the severity of the attack. Blood samples were withdrawn both during the attack and between bronchial asthma attacks.

\section{Extraction procedure}

$1-5 \mathrm{ml}$ of blood was drawn in a heparinized tube (containing $20 \mathrm{ml}$ of ethanol to stabilise cysteinyl-containing leukotrienes) from the asthmatic patients during and between wheezing attacks and from normal healthy individuals. All the samples were collected with the patients' informed consent in accordance with approval of the project from the ethics committee of the Al-Azhar University. Immediately after collection, the blood samples were centrifuged ( $1500 \mathrm{xg}$ for 15 min. at $4^{\circ} \mathrm{C}$ ), then supernatant was stored at $-80^{\circ} \mathrm{C}$ until assayed.

2 - After thawing to $4^{\circ} \mathrm{C}$, the plasma was centrifuged at $15000 \mathrm{xg}$ for $20 \mathrm{~min}$. at $4^{\circ} \mathrm{C}$.

3 - The supernatant was adjusted to $\mathrm{pH} 5.1$ with $0.1 \mathrm{~N} \mathrm{HCl}$ and passed through SEPPAK C ${ }_{18}$ cartridges (Water Associates, Millford, USA), pretreated with $20 \mathrm{ml}$ of pure ethanol followed by $20 \mathrm{ml}$ of distilled water. After the SEP-PAK was successively washed with $20 \mathrm{ml}$ of ethanol-distilled water (1:9), the samples were eluted from the column with $10 \mathrm{ml}$ of methanol.

The methanol fraction was then evaporated under nitrogen and the residue was dissolved in phosphate buffer saline.

\section{Assay procedure}

1 - All the reagents were brought to room temperature and mixed thoroughly without foaming before use.

$2-100 \mu \mathrm{l}$ of standard, buffer or sample was pipetted in duplicate into the antibody precoated wells.

$3-100 \mu \mathrm{l}$ of cysteinyl leukotrienes antibody was added to all wells, except the substrate blank and, in the case of $\mathrm{LTB}_{4}$ determination, $\mathrm{LTB}_{4}$ antibody was added also.

4 - The wells were covered with plate sealer and incubated overnight at $2-8^{\circ} \mathrm{C}$.

$5-100 \mu \mathrm{l}$ of $\mathrm{LTC}_{4}-$ or $\mathrm{LTB}_{4}-$ Alkaline phosphatase conjugate was added to each well and the plate was incubated at $2-8^{\circ} \mathrm{C}$ for 3 hours.

6 - The sealer was removed and the liquid was aspirated from the wells which were washed three times with approximately $400 \mu \mathrm{l}$ of wash buffer per well. 
7 - $300 \mu \mathrm{l}$ of Para-nitrophenyl phosphate substrate solution was added into all wells, and was incubated for 1 hour at $37^{\circ} \mathrm{C}$.

$8-50 \mu \mathrm{l}$ stop solution were pipetted into all wells, including blank wells. The absorbance of the wells was read at $405 \mathrm{~nm}$, versus substrate blank. The $\mathrm{LTC}_{4}$ concentration as $\mathrm{LTB}_{4}$ conc. were calculated as $\mathrm{pmol} / \mathrm{L}$ from the horizontal axis.

\section{Statistics}

Student's t-test was used for statistical analysis of differences between mean values of control and bronchial asthma patients, while t-test of paired sample was used for statistical analyses of differences between mean values during and between attacks for the same patient.

\section{RESULTS}

In bronchial asthma patients the plasma level of cysteinyl-contaning leukotrienes ranged from 159 to $795 \mathrm{pmol} / \mathrm{L}$, with a mean value $500 \pm 31 \mathrm{pmol} / \mathrm{L}(\mathrm{Mean} \pm \mathrm{SE})(\mathrm{n}=31)$ while the level in healthy controls ranged from 75 to $150 \mathrm{pmol} / \mathrm{L}$; mean value $112.1 \pm 8.27$ (Mean \pm SE) $(n=10) \mathrm{P}<0.0001$ (Fig. 1).

The plasma level of spasmogenic cysteinyl leukotrienes during attack of bronchial asthma was significantly higher than the level between attacks (529 \pm 40 and 413 \pm 50.4 ) respectively (Mean \pm SE) $(\mathrm{n}=11) \mathrm{P}<0.002$ (Fig. 2).

Immuno-reactive $\mathrm{B}_{4}$ was detected in all plasma samples. Many of the asthmatic had raised levels ranging from 111 to $1488 \mathrm{pmol} / \mathrm{L}$ with mean $(483 \pm 75)(\mathrm{n}=29)$ while the amount for $\mathrm{LTB}_{4}$ was lower in the plasma of healthy controls ranging from 59 to 208

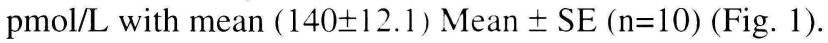

The plasma from asthmatics during attacks had elevated $\mathrm{LTB}_{4}$ compared to the same patients between attacks ( $432 \pm 62$ and $325 \pm 109 \mathrm{pmol} / \mathrm{L}$ Mean \pm SE respectively) $(\mathrm{n}=9)$ (Fig. 2).

\section{DISCUSSION}

In the present study we have demonstrated that spasmogenic cysteinyl leukotrienes and dihydroxy acid leukotriene $\mathrm{B}_{4}$ can be measured in the blood of asthmatic patients by EIA technique after an extraction procedure.

Elevated levels of leukotactic $\mathrm{B}_{4}$ in the plasma of bronchial asthma patients indicate the importance of $\mathrm{LTB}_{4}$ as a mediator of bronchial asthma. A limited number of studies have previously addressed the question of whether leukotriene $\mathrm{B}_{4}$ has a role in bronchial asthma. Uotila et al. (1986) and Shindo et al. (1990) demonstrated that the concentration of $\mathrm{LTB}_{4}$ in arterial blood of asthmatic patients is higher than that of healthy controls ( 250 $\mathrm{pmol} / \mathrm{L}$ in asthmatic patients; $28 \mathrm{pmol} / \mathrm{L}$ in normal subjects). Although the level of $\mathrm{LTB}_{4}$ was low compared with our studies, the findings were based on only five patients and five controls. In the present study we have accumulated data on 34 asthmatic patients and 10 healthy controls.

There have been a few reports concerning the blood level of LTs using direct radioimmunoassay of plasma without prior extraction of HPLC. Hayes et al. (1983) reported that the level of $\mathrm{LTC}_{4}$-like substance was more than $10 \mathrm{nmol} / \mathrm{L}$, also Schonfeld et al. (1985) measured $\mathrm{LTC}_{4}$ in plasma. Its mean value in asthmatics was $63.9 \mathrm{nmol} / \mathrm{L}$ and that 


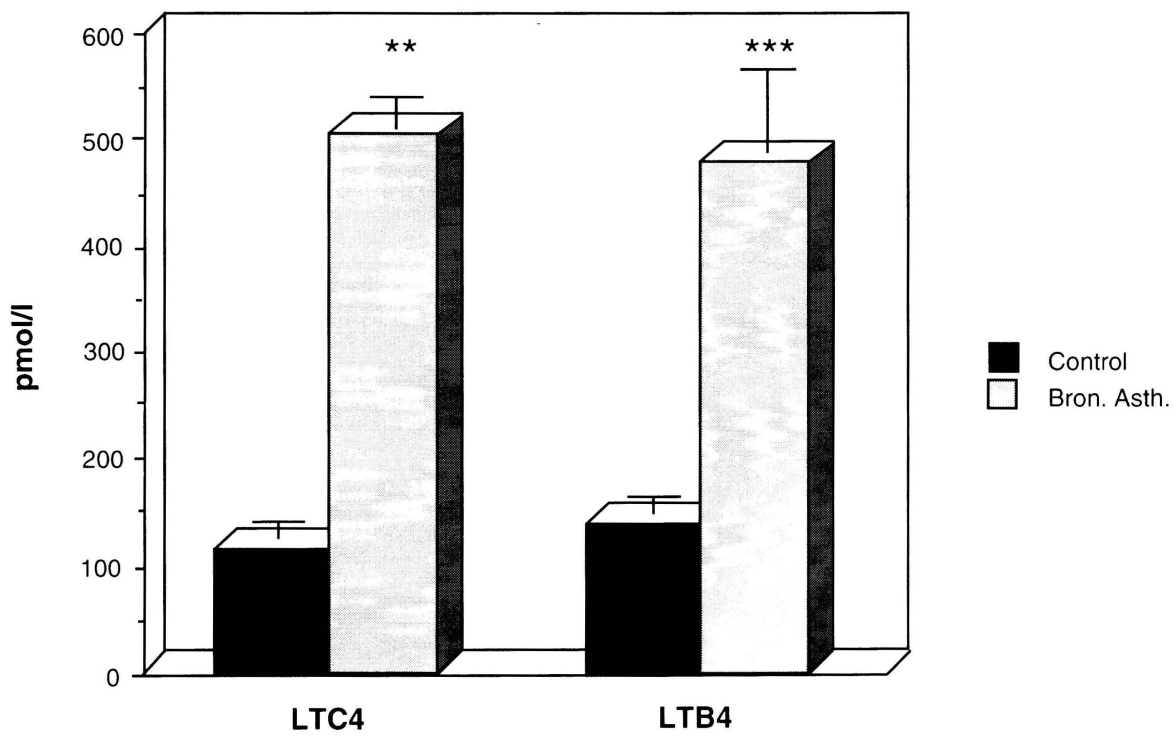

Figure 1. Plasma level of leukotrienes in bronchial asthma patients $* * * \mathrm{P}>0.001$

** $\mathrm{P}>0.01$

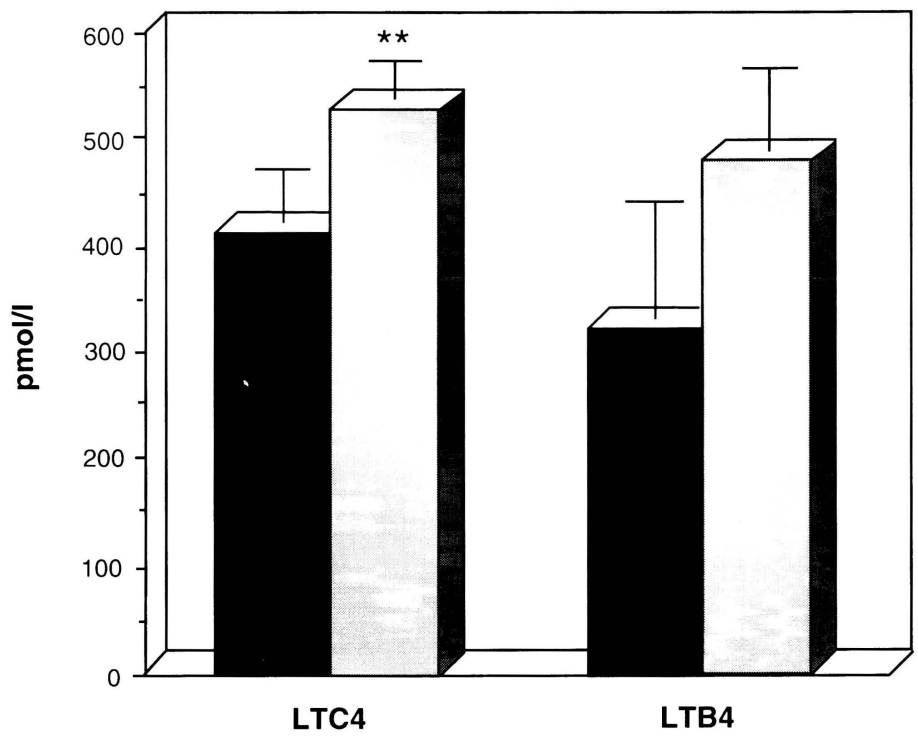

Figure 2. Plasma level of leukotrienes between and during attacks of bronchial asthma. $* * \mathrm{P}>0.01$ 
of normal subjects was $8-16 \mathrm{nmol} / \mathrm{L}$. There are possibilities that direct radioimmunoassay without prior extraction may be affected by unknown cross-reacting substances in blood and that non specific interference by proteins or lipids might take place.

Human plasma is known to degrade $\mathrm{LTC}_{4}$ and $\mathrm{LTD}_{4}$ to $\mathrm{LTE}_{4}$ rapidly (Parker et al., 1980 ) indicating that $\mathrm{LTE}_{4}$ is likely to be a significant product of SRS-A metabolism in vivo so the EIA reagents which we used in the present study include antibodies directed against all cysteinyl-containing leukotrienes.

Dahlen et al. (1980) reported that $\mathrm{LTC}_{4}, \mathrm{LTD}_{4}$, and $\mathrm{LTE}_{4}$ were released from the lung tissues of asthmatic after antigen challenge. The amount of $\mathrm{LTE}_{4}$ was less than $\mathrm{LTC}_{4}$ and $\mathrm{LTD}_{4}$. They also reported that human bronchi contracted on exposure to $6.2 \mathrm{nmol} / \mathrm{L}$ of $\mathrm{LTD}_{4}$. The average level of spasmogenic cysteinyl leukotrienes in the present study is $500 \mathrm{pmol} / \mathrm{L}$. The bronchoconstrictor concentration was thus approximately 12 times higher than the plasma level recorded in the present study. Since we sampled blood from the systemic circulation, there is substantial dilution of $\mathrm{LTC}_{4}$ from the bronchiolar extracellular fluid. Therefore we think that the plasma level of cysteinyl leukotrienes in the present study is compatible with the in vitro study using human bronchi. Okubo et al. (1987) reported that there was no correlation between the level of plasma leukotrienes and pulmonary function tests such as forced expiratory volume (FEV) or airway resistance (Raw).

Leukotrienes are formed by leukocytes, Arachidonic acid is released and metabolized to leukotrienes in the leukocytes of asthmatic patients. $\mathrm{LTB}_{4}$ has been reported to be formed in stimulated polymorphnuclear leukocytes and $\mathrm{LTC}_{4}$ predominantly in stimulated eosinophils especially in the presence of gluthatione (Verhagen et al., 1984; Borgeat et al., 1984). The precise relationship between the development of asthma, and the high concentrations of leukotrienes $\mathrm{B}_{4}$ and $\mathrm{C}_{4}$ present in arterial blood is however still unclear. It will be necessary to examine in more detail the changes in levels of leukotrienes $\mathrm{C}_{4}$ and $\mathrm{B}_{4}$ in arterial blood of the same patients throughout the clinical course of bronchial asthma, if this proves to be ethically acceptable.

\section{REFERENCES}

Borgeat, P., Fruteau de Laclos, B., Rabinovitch, H., Picard, S., Braquet. P.. Hebert. J. Lviolette, M. (1984). Eosinophil-rich polymorphonuclear leukocyte preparations characteristically release leukotriene $\mathrm{C}_{4}$ on ionophore $\mathrm{A} 23187$ challenge. J. Allergy Clin. Immunol., 74, 310-314.

Dahlen, S.-E., Hedqvist, P., Hammarström, S., Samuelssom. B. (1980). Leukotrienes are potent constrictors of human bronchi. Nature, 288, 484-486.

Hayes, E.C., Lombardo, D.L., Girard, Y., Maycock, A.L.. Rokach. J., Rosenthal, A.S. et al. (1983). Measuring leukotrienes of slow reacting substance of anaphylaxis, development of specific radioimmunoassay. J. Immunol. 131, 429-433.

Murphy, R.C., Hammarström, S., Samuelsson, B. (1979). Leukotriene C: A slow reacting substance from murine mastocytoma cells. Proc. Natl. Acad. Sci. USA, 76, 4275-4279.

Parker, C.W., Koch, D., Huber, M., Falkenheim, S.F. (1980). Formation of the cysteinyl form of slow reacting substance (Leukotrienes $\mathrm{E}_{4}$ in human plasma). Biochem. Biophys. Res. Commun., 97, 1038-1047.

Samuelsson, B. (1983). Leukotrienes: Mediators of immediate hypersensitivity reactions and inflammation. Science, 220, 568-575

Samuelsson, B. Dahlen, S.-E., Lindgren, J.Ä., Rouzer, C.A., Serhan, C.N. (1987). Leukotrienes and lipoxins: structures, biosynthesis and biological effects. Science, 237, 1171-1176.

Schönfeld, W., Köller, M., Knöller, J., König Muller, W., Hardt, H.v.d. (1985). Leukotrienes and 
their metabolism in plasma and bronchial fluids. J. Allergy Clin. Immunol., 75, 126.

Shindo, K., Matsumoto, Y., Hirai, Y., Sumitomo, M., Amano, T., Miyakawa, K. et al. (1990). Measurement of leukotriene $\mathrm{B}_{4}$ in arterial blood of asthmatic patients during wheezing attacks. J. Int. Med., 228, 91-96.

Stechschulte, D.J., Orange, R.P., Austen, K.F. (1973). Detection of slow reacting substance of anaphylaxis (SRS-A) in plasma of guinea pig during anaphylaxis. J. Immunol., 111, 1585-1589.

Uotila, P., Punnonen, K., Tammivaara, R., Jansen, C.T. (1986). Detection of leukotrienes in the serum of asthmatic and psoriatic patients. Acta Derm. Venereol., 66, 381-385.

Verhagen, J., Bruynzeel, P.L.B., Koedam, J.A., Wassink, G.A., de Boer, M., Terpstra, G.K. et al. (1984). Specific leukotriene formation by purified human eosinophils. FEBS Lett., 168, 23-28.

Ökubo, T., Takahashi, H., Sumitomo, M., Shindoh, K., Suzuki, S. (1987). Plasma levels of leukotrienes $\mathrm{C}_{4}$ and $\mathrm{D}_{4}$ during wheezing attack in Asthmatic patients. Int. Arch. Allergy Appl. Immunol., 84, 149-155. 


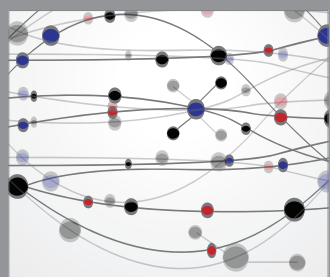

The Scientific World Journal
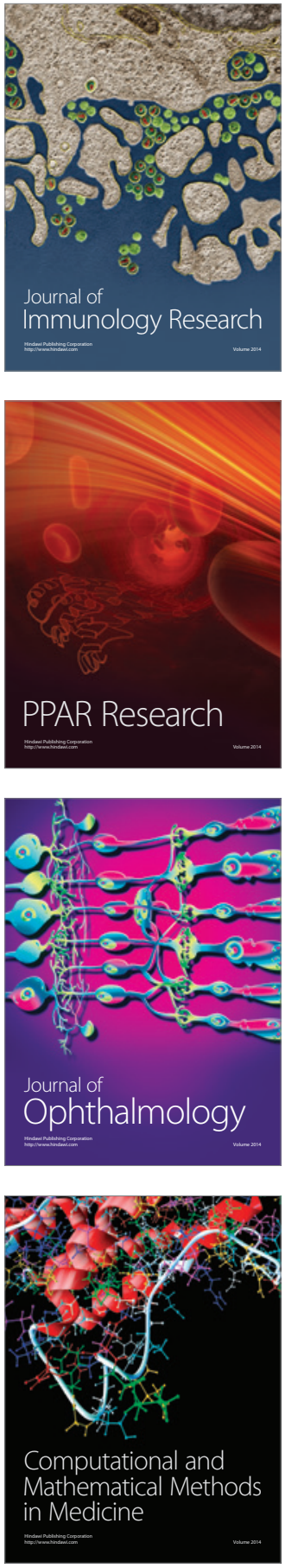

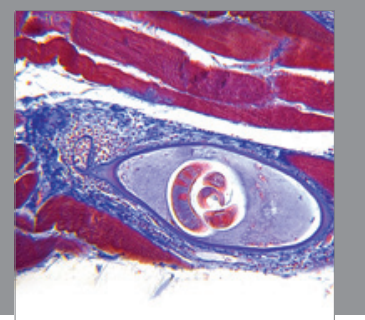

Gastroenterology

Research and Practice
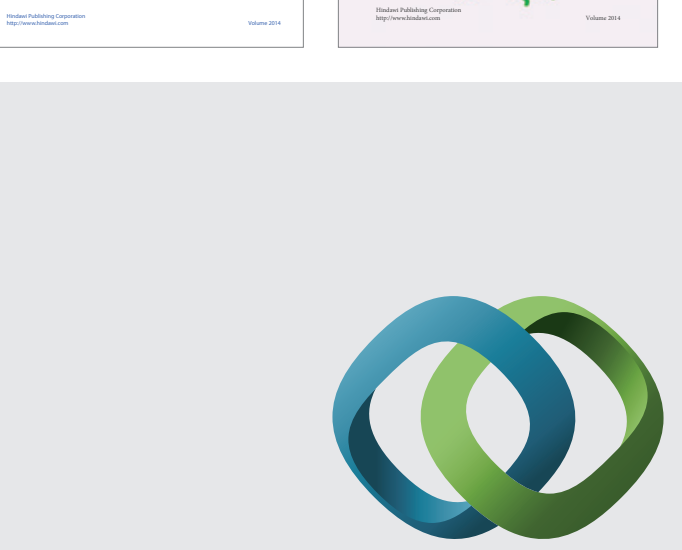

\section{Hindawi}

Submit your manuscripts at

http://www.hindawi.com
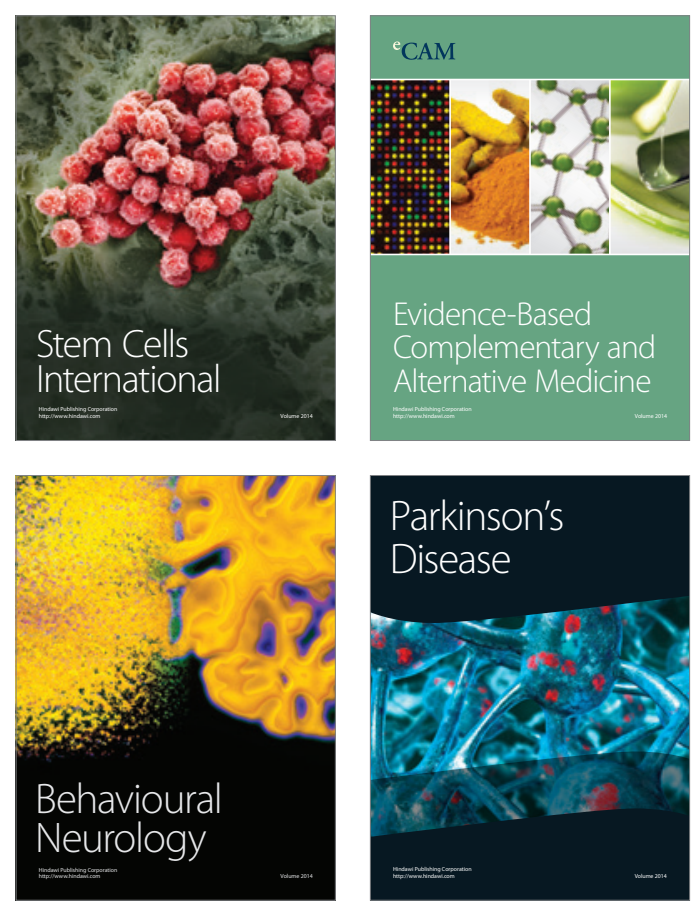

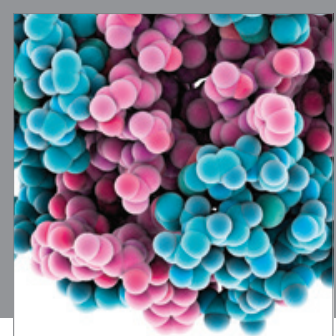

Journal of
Diabetes Research

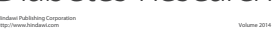

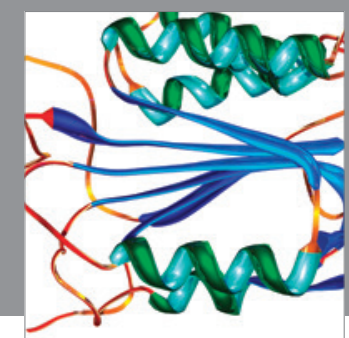

Disease Markers
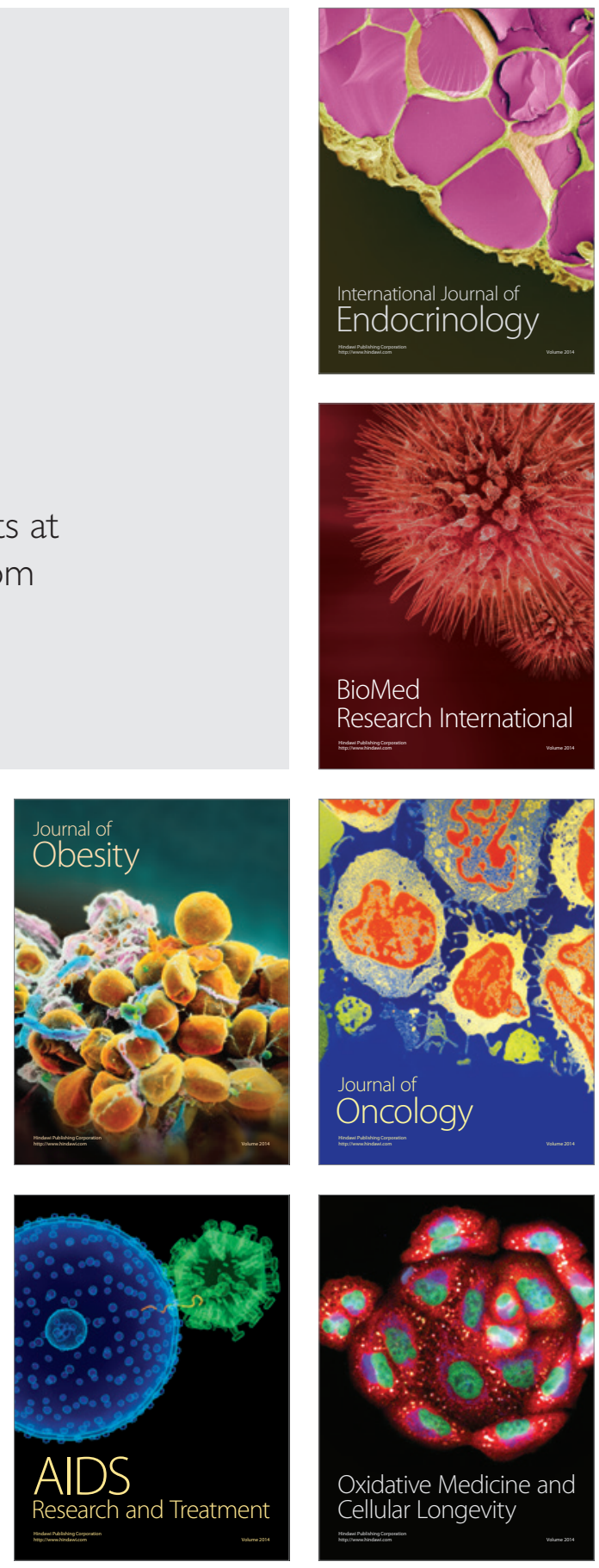